\title{
Genes Influencing the Conversion of Gitrulline to Argininosuccinate in Neurospora crassa
}

\author{
BY DOROTHY NEWMEYER \\ Department of Biological Sciences, Stanford University, Stanford, California, U.S.A.
}

(Received 8 August 1961)

\begin{abstract}
SUMMARY
The enzymic conversion of citrulline $\rightarrow$ argininosuccinate $\rightarrow$ arginine in wild-type Neurospora crassa has been shown to be essentially like that in mammalian tissues in all respects tested. The enzymes responsible for the two reactions (condensing enzyme and argininosuccinase) have been partially separated. Five mutants at the arg- 1 locus have normal argininosuccinase and little or no condensing activity. The lack of condensing activity appears to be due to a simple absence of enzyme, alternatives such as inhibitor production or increased ATPase competition having been ruled out. Small amounts of apparent condensing activity, detected in the substrate-disappearance assay, were shown to be due to side reactions. When grown at the usual high arginine concentrations, three mutants at the arg-10 locus, which are known to lack argininosuccinase, have normal condensing activity. However, when arg-10 strains are grown at low arginine concentrations, the resulting extracts have very little condensing activity. This also appears to be due to a simple loss of condensing enzyme. It has not been determined whether the low activity is a specific secondary effect of arg-10 on the condensing enzyme, or whether it is merely a non-specific effect of the inadequate supplementation, which might cause reductions in many enzyme activities. Despite its very low condensing activity in vitro, arg-10 grown at low arginine concentrations must be active at some time in vivo, since its mycelium accumulates argininosuccinate but not citrulline. In contrast, an arg-1 arg-10 double mutant, grown at low arginine concentrations, must be inactive in vivo, since it accumulates citrulline but not argininosuccinate. It is concluded that arg-1 is probably the primary locus controlling the synthesis of condensing enzyme.
\end{abstract}

\section{INTRODUCTION}

Numerous studies of gene-enzyme relationships suggest that a single genetic locus determines the basic ability to form a given enzyme, but that the quantity of the enzyme produced can be modified by other genes and by varying environmental conditions (see review by Fincham, 1958; Yanofsky \& St Lawrence, 1960). The present paper is an analysis of similar gene-enzyme relationships concerned with the conversion of citrulline to arginine in Neurospora crassa. The mechanism of this conversion in mammalian tissues has been studied extensively by Ratner and co-workers (Ratner \& Petrack 1951, 1953 a, b, 1956; Ratner, Petrack \& Rochovansky, 1953). They found that two reactions were involved:

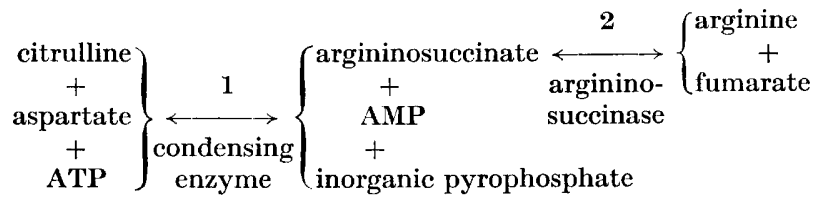


The condensation of citrulline and aspartate to form argininosuccinate (reaction 1) is greatly accelerated by the presence of inorganic pyrophosphatase (Ratner \& Petrack, 1956).

Evidence is presented here that citrulline is converted to arginine in wild-type Neurospora crassa in essentially the same way as in mammalian tissues. Independently Boylen \& Fincham (personal communication) have obtained preliminary evidence for the same reaction sequence in wild-type Neurospora, and have studied the argininosuccinase reaction in detail (Fincham \& Boylen, 1957). Nine mutant strains blocked between citrulline and arginine have been classified genetically into two types, representing mutations at two unlinked loci (Newmeyer, 1957); these are called arg-1 and arg-10. Fincham \& Boylen (1957) have shown that arg-10 mutants lack argininosuccinase. 'The present paper is concerned with the effects of the two loci on the condensation reaction.

\section{METHODS}

Strains. The origin and genetic analysis of the mutants were described previously (Newmeyer, 1957). The following stocks were used:

arg-1 (Linkage group I; uses arginine but not citrulline): alleles $36703 \mathrm{~T}, 46004$, $\mathrm{H} 4250, \mathrm{~B} 312$, and B369.

arg-3 (Linkage group I; uses citrulline or arginine): allele $\mathbf{3 0 3 0 0 .}$

arg-10 (Linkage group VII; uses arginine but not citrulline): alleles B317, B 368, and B370.

wild-type: ST-74A.

All mutants were inbred to the wild type.

The arg-1 arg-10 double mutant was isolated from a non-parental ditype ascus from a cross of inbred lines of $\mathbf{3 6 7 0 3 \mathrm { T }}$ and B317. Its constitution was verified by crossing to wild type and recovering both single mutants from the same ascus.

Enzyme preparations. Cultures were grown in Erlenmeyer flasks at $30^{\circ}$ with moderate shaking. Each flask contained $650 \mathrm{ml}$. Fries minimal medium (Beadle \& Tatum, 1945) containing $20 \mathrm{~g}$. sucrose per 1. , with or without arginine, as indicated in Results. The mycelia were harvested by filtration, washed with distilled water, sucked dry, and ground in a cold mortar with an equal weight of alumina powder (Buehler's Levigated, no. 1557 AB). The mixture was extracted with cold $0 \cdot 01 \mathrm{M}$-phosphate buffer $(\mathrm{pH} 7 \cdot 4)$, centrifuged at $21,600 \mathrm{~g}$ for $30 \mathrm{~min}$. at $5^{\circ}$, and the extract stored at $-15^{\circ}$. Dialyses were carried out against $0.01 \mathrm{~m}$-phosphate buffer ( $\mathrm{pH} 7 \cdot 4$ ) at $5^{\circ}$ overnight. Crude extracts containing about $15 \mathrm{mg}$. protein $/ \mathrm{ml}$. were fractionated with solid ammonium sulphate at $0^{\circ}$ as shown in Table 1. A sample of the $\mathbf{2 5 - 5 0} \%$ fraction was diluted to about $9 \mathrm{mg}$. protein $/ \mathrm{ml}$. and refractionated with ammonium sulphate as shown in Table 1. Precipitates were dissolved in

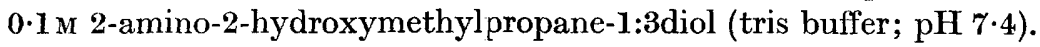

Chemicals and analytical methods. The colorimetric methods used for determining arginine, citrulline, urea and inorganic phosphate, as well as the preparation of reagents, substrates and supplementary enzymes, were all as described by Ratner (1955) and Ratner \& Petrack (1951, 1953 b) except as noted. Extracts of urease (Nutritional Biochemicals Corporation) were made fresh each day, $50 \mathrm{mg}$. being extracted with $5 \mathrm{ml}$. water or $(\cdot 1 \mathrm{M}$-phosphate buffer $(\mathrm{pH} 7 \cdot 4)$; these extracts did 
not interfere in any of the assay procedures. Protein was estimated by the biuret method (Gornall, Bardawill \& David, 1949) on samples clarified by repeated centrifugation.

Measurement of condensing activity. The complete assay system contained (in $\mu$ mole per $2 \mathrm{ml}$.): 15, L-citrulline; $15 \mathrm{~L}$-aspartate; $13.2 \mathrm{MgSO}_{4} ; 100$ tris or phosphate buffer (pH 7·4); 2.5 A'TP; 25 to 75, D-3-phosphoglycerate (PGA). (The PGA was used to regenerate ATP. In Neurospora extracts, ATPase activity is much greater than condensing activity, so that 60 or more $\mu$ mole PGA were often necessary in order to achieve linear reaction rates. It was found unnecessary to add an outside source of the enzymes needed to regenerate ATP from PGA, even when fractions were being assayed.) The mixtures were incubated at $33^{\circ}$ and the reactions stopped with trichloroacetic acid (TCA).

Table 1. Separation of condensing and argininosuccinase activities in wild type Neurospora crassa

\begin{tabular}{|c|c|c|c|c|c|c|}
\hline \multirow[b]{2}{*}{ Fraction no. } & \multirow[b]{2}{*}{$\begin{array}{c}\left(\mathrm{NH}_{4}\right)_{2} \mathrm{SO}_{4} \\
\text { saturation } \\
(\%)\end{array}$} & \multirow[b]{2}{*}{$\begin{array}{c}\text { Protein } \\
\text { (mg.) }\end{array}$} & \multicolumn{2}{|c|}{ Condensing activity } & \multicolumn{2}{|c|}{ Argininosuccinase } \\
\hline & & & $\begin{array}{l}\text { Specific } \\
\text { activity* }\end{array}$ & $\begin{array}{l}\text { Total } \\
\text { units } \dagger\end{array}$ & $\begin{array}{c}\text { Approximate } \\
\text { specific } \\
\text { activity* }\end{array}$ & $\begin{array}{c}\text { Approximate } \\
\text { total } \\
\text { units } \dagger\end{array}$ \\
\hline Crude extract & - & 3090 & 0.59 & 1823 & $0 \cdot 76$ & 2350 \\
\hline I & $0-25$ & 103 & $\mathbf{0}$ & 0 & $\leqslant 0 \cdot 20$ & $0-21$ \\
\hline II & $25-50$ & 1740 & $0 \cdot 86$ & 1498 & 0.86 & 1498 \\
\hline III & $50-85$ & 842 & $\leqslant 0.035$ & $0-29$ & $\leqslant 0.03$ & $0-25$ \\
\hline $\mathrm{II}_{+}^{+}$ & $25-50$ & 739 & $0 \cdot 86$ & 635 & 0.86 & 635 \\
\hline II $a$ & $0-30$ & 214 & $\leqslant 0.05$ & $0-11$ & $0 \cdot 13$ & 28 \\
\hline II $b$ & $30-44$ & 284 & $1 \cdot 01$ & 287 & $2 \cdot 03$ & 577 \\
\hline II $c$ & $44-70$ & 187 & $1 \cdot 68$ & 314 & 0.01 & 2 \\
\hline
\end{tabular}

* Units/mg. protein.

$\dagger$ One unit caused the disappearance of $1 \mu$ mole citrulline or formation of $1 \mu$ mole arginine in 1 hr. at $33^{\circ}$.

\$ The sample used for refractionation.

Condensation was assayed by measuring citrulline disappearance colorimetrically (Ratner, 1955). (Neurospora extracts contain too much urease to permit the assay of condensing activity by measuring urea production.) With the wild type, the citrulline disappearance method is reliable, since no side-reactions have been detected at the protein concentrations used for assay. With the mutants, however, this assay presents two difficulties.

(1) Citrulline disappearance might be due to side-reactions, because much larger amounts of protein must be tested in order to detect small amounts of condensing activity. Furthermore, citrulline accumulation resulting from a genetic block might induce the synthesis of enzymes catalysing such side-reactions. Therefore, the apparent small activity found in arg-1 extracts was tested for its relevance to condensation by dependency tests, and by testing for argininosuccinate production by two-dimensional chromatography.

(2) With arg-1 extracts it is hard to obtain accurate citrulline disappearance measurements without increasing the time and/or amount of enzyme so much that the linear range is exceeded; the enormous ATPase competition under these conditions often makes it impossible to add an excess of PGA. The arg-1 'specific 
activity' values given under Result; are therefore only best estimates, and are shown bracketed when the only assays were definitely in the non-linear range. In order to show that the difference between $\arg -1^{-}$and $\arg -1^{+}$is nevertheless real, typical raw data are also given whi $2 h$ compare $\arg -1^{-}$and $\arg -1^{+}$extracts when both are assayed under similar conditions, at high time and enzyme levels.

All assays of citrulline disappearance were made on dialysed extracts, because undialysed extracts, particularly of arg-1 mutants, contain material which gives colour in the citrulline assay; only part of this can be citrulline itself. Urea also interferes in the citrulline determination, but in crude extracts it is destroyed as fast as formed. In at least one assay on each extract, the enzymic reaction was stopped by heat and the mixture re-incubited with excess urease before citrulline was determined. This procedure always gave the same results as when urease was omitted.

Arginine desimidase (Oginsky \& Gehrig, 1952) was not expected to interfere seriously because of its sensitivity to $\mathrm{Ig}^{++}$and its low activity at $\mathrm{pH} \mathbf{7} \cdot \mathbf{4}$; desimidase activity was specifically shown to be absent from wild-type fraction II under the conditions used here.

Measurement of argininosuccinase. An approximate assay was obtained by determining the amount of $\mathrm{CO}_{2}$ formed in the presence of excess arginase and urease. Double-armed Warburg vessels were used; the main compartment contained $0 \cdot 10 \mathrm{ml}$. arginase solution, $0.20 \mathrm{ml}$. urease solution (buffer extract), $0.20 \mathrm{ml}$. of $1 \cdot 0 \mathrm{M}$ phosphate buffer $(\mathrm{pH} 7 \cdot 4)$, and dialysed Neurospora extract in a total volume of $0.70 \mathrm{ml}$. The reaction was started by tipping in $0.30 \mathrm{ml}$. of a solution containing $6 \mu$ mole argininosuccinate. Standa d manometric procedures were used, with air as gas phase. Endogenous respiration was negligible. $\mathrm{CO}_{2}$ production was linear with time so long as $25 \%$ of the substrate remained.

Measurement of ATPase. For est mating ATPase competition, crude assays were made by measuring the total inorganic phosphate liberation in the TCA filtrates used for measuring citrulline disappearance; the complete system was used except that ATP (20 $\mu$ mole $/ 2 \mathrm{ml}$.) was used as sole phosphate donor. Most of the phosphate liberation was due to ATPase; apr roximate correction for the small amount that could be due to condensation (0-30\% of the total) was based on the citrulline disappearance measurements. For measuring the ratio of phosphate liberation to citrulline disappearance, exact correction was made for ATPase, and also for a trace reaction involving aspartate, by subtracting the phosphate liberated in the absence of citrulline from the amount liberated when both amino acids were present.

Chromatography. Ascending paper chromatography was used to detect the formation of argininosuccinate and other products by the Neurospora extracts. Only dialysed extracts were used. Incubation mixtures were made with phosphate buffer since tris buffer altered the $\boldsymbol{K}_{F}$ values of several compounds. After incubation the mixtures were deproteinized by heating and chromatographed either with $4+1+2$ by vol. butanol + acetic acid + water (run twice in the same direction) or with $3+1$ by vol. phenol + water with or without ammonia atmosphere. For twodimensional chromatograms, phenıl without ammonia was used as the first solvent and butanol + acetic acid as the second; in this case it was not essential to develop twice with butanol + acetic acid. With the incubation mixtures used here, one- 
dimensional phenol chromatograms rarely gave adequate separation of argininosuccinate from glutamate, and one-way butanol + acetic acid chromatograms failed to separate argininosuccinate from aspartate. Argininosuccinate was therefore identified by two-dimensional chromatography, and by elution and re-development, with similarly eluted authentic argininosuccinate as a standard. All critical identifications were checked by addition of known amino acids.

\section{RESULTS}

\section{Neurospora crassa wild type}

Extracts of wild-type Neurospora readily catalysed the disappearance of citrulline and the appearance of arginine in the presence of the complete system. The enzymes involved are quite stable to dialysis and storage. The rate of citrulline disappearance for various wild-type extracts is given in Table 2 ; this rate was affected very little by the presence or absence of arginine in the culture medium. The wild-type Neurospora system resembles the mammalian one in all respects tested. Specifically:

(1) In dialysed fractionated material, both citrulline disappearance and arginine formation were completely dependent on the presence of aspartate, citrulline, $\mathrm{MgSO}_{4}$ and ATP. Aspartate could not be replaced by ammonium ion or glutamate.

(2) The rate of citrulline disappearance was greatest when a combination of D-3-phosphoglycerate + a catalytic amount of ATP was used as the source of highenergy phosphate, since high ATP concentrations inhibited the reaction. In the absence of D-3-phosphoglycerate, activity was decreased at ATP concentrations greater than $20 \mu$ mole $/ 2 \mathrm{ml}$; this concentration gave only $50-80 \%$ of the activity obtained with $2 \cdot 5 \mu$ mole ATP + optimal concentrations of D-3-phosphoglycerate (Table 2).

(3) The reaction is accompanied by a liberation of inorganic phosphate which depends on the simultaneous presence of citrulline and aspartate. The ratio of phosphate liberation to citrulline disappearance was determined using fraction II with $2 \cdot 5 \mu$ mole ATP $+45 \mu$ mole D-3-phosphoglycerate; after correcting for phosphate liberated by ATPase, values of $1.53,1.53$, and 1.49 were obtained. In liver, the $\Delta$ phosphate/ $\Delta$ citrulline ratio is typically between $\mathbf{1} \cdot 0$ and $\mathbf{2 \cdot 0}$, the exact value depending on the concentration of inorganic pyrophosphatase and on the source of ATP. When ATP was supplied from D-3-phosphoglycerate, values of about 1.5 were obtained only when the pyrophosphatase concentration was nearly optimal (Ratner \& Petrack 1953a, 1956). The Neurospora results therefore suggest that pyrophosphatase is similarly involved in its condensing system, and is probably not seriously limiting. Pyrophosphatase is evidently not removed by the partial purification used here, since there is little loss of condensing activity during fractionation (Table 1).

(4) The reaction occurs in two steps with argininosuccinate as intermediate. The evidence for this is as follows. Citrulline disappearance always exceeded arginine formation. (No attempt was made to achieve equilibrium.) Partial purification gave two active fractions (Table 2). One (II $b$ ) caused a rapid disappearance of citrulline, of which $55 \%$ was found as arginine; this fraction contained most of the argininosuccinase. The other active fraction (II $c$ ) caused a more rapid disappearance 


\section{Table 2. Condensing activities of mutant and wild-type extracts}

Specitic activities are based on measurements of eitrulline disappearance in dialysed crude extracts. 'PGA system' indicates complete incubation mixture with $2 \cdot 5 \mu$ mole ATP + optimal concentrations of $\mathrm{D}-3$-phosphoglycerate (PGA) as described in Methods. 'ATP system' indicates complete incubation mixture with $20 \mu$ mole ATP and no PGA. For arg- $1^{+}$strains, incubation was fo $\mathrm{r}$ 1-4 hr., with 1-4 mg. protein. For arg-1- it was necessary to use more protein. Wher: this resulted in non-linearity, the specific activity values are enclosed in brackets; in suc $h$ cases the raw data indicate decidedly less activity than is given by arg- $1^{+}$under similar conditions. See Methods and Table 3.

\begin{tabular}{|c|c|c|c|c|c|c|}
\hline \multirow[b]{2}{*}{ Genotype } & \multirow[b]{2}{*}{ Allele } & \multirow[b]{2}{*}{ Extrat no. } & \multicolumn{2}{|c|}{ Growth conditions } & \multicolumn{2}{|c|}{ Specitic activity } \\
\hline & & & $\begin{array}{l}\text { No. } \\
\text { days }\end{array}$ & $\begin{array}{l}\text { Arginine } \\
\text { (mg./ml.) }\end{array}$ & $\begin{array}{c}\text { PGA } \\
\text { system }\end{array}$ & $\begin{array}{c}\text { ATP } \\
\text { system }\end{array}$ \\
\hline \multirow{6}{*}{ Wild type } & $\mathrm{S}^{\prime} \mathrm{l}^{\prime}-74 \mathrm{~A}$ & 5 & 3 & 0 & 0.59 & - \\
\hline & $S T-74 A$ & 11 & 3 & $0 \cdot 2$ & $0 \cdot 46$ & $0 \cdot 30$ \\
\hline & ST-74A & 13 & 3 & $0 \cdot 2$ & $0 \cdot 63$ & - \\
\hline & $\mathrm{S}^{\prime} \mathrm{I}-74 \mathrm{~A}$ & 15 & 5 & 0 & 0.57 & $0 \cdot 46$ \\
\hline & ST'-74A & 17 & 5 & $0 \cdot 2$ & 0.79 & $0 \cdot 39$ \\
\hline & $S^{\prime} T^{\prime}-74 A$ & 19 & $1 \cdot 8$ & 0.07 & $0 \cdot 62$ & - \\
\hline \multirow{7}{*}{$\begin{array}{l}\operatorname{arg-3} \\
\operatorname{arg-10}\end{array}$} & $30300 a$ & 26 & 5 & $0 \cdot 2$ & $0 \cdot 71$ & $\ldots$ \\
\hline & $B 317 \mathfrak{a}$ & 24 & 5 & $0 \cdot 2$ & $0 \cdot 41$ & 0.29 \\
\hline & В370a & 30 & 5 & $0 \cdot 2$ & $0.46-0 \cdot 53$ & $0 \cdot 16-0 \cdot 18$ \\
\hline & B $368 a$ & 32 & 5 & $0 \cdot 2$ & $0.35-0 \cdot 43$ & $0 \cdot 17-0 \cdot 21$ \\
\hline & B317a & 38 & 3 & $0 \cdot 5$ & 0.48 & $0 \cdot 28$ \\
\hline & B317a & 60 & 3 & 0.5 & 0.51 & - \\
\hline & $\mathrm{B} 370 \mathrm{a}$ & 64 & 3 & 0.5 & $0 \cdot 60$ & - \\
\hline \multirow[t]{12}{*}{$\arg -1$} & $36703 \mathrm{~T}-\mathrm{a}$ & 4 & 5 & $0 \cdot 2$ & $0 \cdot 06^{*}$ & - \\
\hline & 36703' $\mathrm{C}-\mathrm{A}$ & 120 & 5 & $0 \cdot 2$ & $\ldots$ & 0.07 \\
\hline & 3670:3'T-A & $12 I^{\prime}$ & 5 & $0 \cdot 2$ & - & $0 \cdot 11$ \\
\hline & 36703 'T-A & $16 \mathrm{C}$ & 5 & $0 \cdot 2$ & 0.08 & $0 \cdot 10$ \\
\hline & $36703 \mathrm{~T}-\mathrm{A}$ & $16 I$ & 5 & $0 \cdot 2$ & - & 0.04 \\
\hline & $46004 \mathrm{~A}$ & 14 & 5 & $0 \cdot 2$ & $0 \cdot 06$ & {$[0.03]$} \\
\hline & $46004 a$ & 44 & 5 & $0 \cdot 2$ & {$[0 \cdot 03]$} & - \\
\hline & $13369 \mathrm{a}$ & 20 & 5 & $0 \cdot 2$ & 0.08 & 0.09 \\
\hline & $\mathrm{H} 42250 \mathrm{~A}$ & $22 \mathrm{C}$ & 5 & $0 \cdot 2$ & $0 \cdot 10$ & $0 \cdot 13$ \\
\hline & $\mathrm{H} 4250 \mathrm{~A}$ & $22 \mathrm{D}$ & 5 & $0 \cdot 2$ & 0.12 & $0 \cdot 14$ \\
\hline & H $4: 250 \mathrm{a}$ & 46 & 5 & $0 \cdot 2$ & {$[0.06]$} & - \\
\hline & $\mathrm{B} 312 \mathrm{a}$ & 10 & 4 & $0 \cdot 2$ & 0.04 & {$[0 \cdot 02]$} \\
\hline arg-1 arg-10 & $36703 \mathrm{~T}-1 \mathrm{~B} 317$ & 18 & 5 & $0 \cdot 2$ & - & $0.02 *$ \\
\hline (double mutant) & 36703 'T-B317 & 42 & 3 & 0.5 & {$[0 \cdot 02]$} & $0 \cdot 01 *$ \\
\hline
\end{tabular}

* Not signific antly greater than zero.

of citrulline, of which not more than $5 \%$ was found as arginine; this fraction contained very little argininosuccinase and negligible arginase. It was shown by sequential incubations that fraction II $c$ converted the missing citrulline to an intermediate compound, which could be converted to arginine by an argininosuccinase preparation from yeast. 'This preparation, the $\mathbf{3 5 - 5 0 \%}$ ammonium sulphate fraction from a plasmolysed extract of baker's yeast, had negligible condensing activity.) The intermediate was identified as argininosuccinate by paper chromatography. When incubated $\mathrm{w}$ th the complete system, the dialysed crude extract and fraction II each produced both arginine and argininosuccinate, while fraction II $c$ and a dialysed crude ext act of arg-10(B 317$)$ each produced a strong argininosuccinate spot but never mort than a dubious arginine spot. (Arginine was 
detectable because, in the presence of the filtrates, it was displaced upward on phenol chromatograms, in the absence of ammonia, to $\boldsymbol{R}_{F} \mathbf{0 \cdot 7 0}$, and was thus separated from citrulline. Under the same conditions, ornithine was displaced downward, so as to be superimposed on slow-moving material present in all mixtures before incubation; the expected traces of ornithine were therefore not detectable.) No other products were found. By using fraction II, detectable argininosuccinate production was found to be completely dependent on the presence of citrulline, aspartate, $\mathrm{MgSO}_{4}$ and $\mathrm{A}$ TP.

\section{Neurospora crassa mutants}

Condensing activity at standard growth conditions. Extracts of the arg-1 and arg-10 mutants (and also of the citrullineless mutant, arg-3) were ordinarily prepared from mycelia grown for 5 days on minimal medium $+0.2 \mathrm{mg}$. arginine $/ \mathrm{ml}$; ; few strains were also grown for 3 days at $\mathbf{0 . 5} \mathrm{mg} . / \mathrm{ml}$. The condensing activities of these preparations are summarized in Table 2 as specific activities, and typical raw data comparing $\arg -1^{+}$with arg- $1^{-}$are given in Table 3 . The arg-1 extracts invariably caused much less citrulline disappearance than the wild-type controls, although they were not completely inactive. Extracts of arg-10 and arg-3, on the other hand, were essentially as active as wild type. As expected, the arg-1 arg-10 double mutant showed the reduced activity characteristic of arg-1.

The low activities of the arg-1 extracts were not due merely to a deficiency in the enzymes which regenerate ATP from D-3-phosphoglycerate. This is shown, first, by the results with ATP as sole phosphate donor (Tables 2 and 3). The difference between $\arg -1^{-}$and $\arg -1^{+}$activities was smaller here than with the D-3-phosphoglycerate system, because the arg- $1^{-}$extracts did not show the ATP inhibition characteristic of liver and wild-type Neurospora. Even so, there was still no overlap in the activities of $\arg -1^{+}$and $\arg -1^{-}$. Secondly, when extracts from three different arg-1 mutants were assayed with the D-3-phosphoglycerate system, addition of a muscle preparation to supply the enzymes needed for regenerating ATP (Ratner, 1955) caused no increase in condensing activity.

Mixing crude extracts of arg- 1 with active control extracts caused no significant stimulation or inhibition ('Table 4). As a further test, arg-1 extract no. 4 was put through a single ammonium sulphate fractionation. The resulting fraction II, which should have contained all the condensing activity, was still quite inactive, and caused no stimulation or inhibition when combined with wild-type fraction II (Table 4). The mutant fraction II also caused no stimulation when combined with the inactive wild-type fractions I, II $a$, and III. (A small amount of activity was found in mutant fraction III, however. The residual arg-1 activity thus fractionated abnormally, suggesting that it might be due to a different enzyme.)

The low activity of the arg-1 extracts does not appear to be ascribable merely to increased ATPase activity. ATPase assays on various extracts of the wild type, $\arg -1(36703 T)$, arg-10(B 317), and the $\arg -1 \arg -10$ double mutant, showed that while this activity varied considerably, depending on the growth conditions, it was unaffected by the presence or absence of arg-1- . Excessive ATPase competition was further excluded by the lack of inhibition when arg-1 extracts were combined with wild type (Table 4). The lack of inhibition also makes it unlikely that the low activity of the arg-1 extracts was due to a large increase in arginine desimidase. 


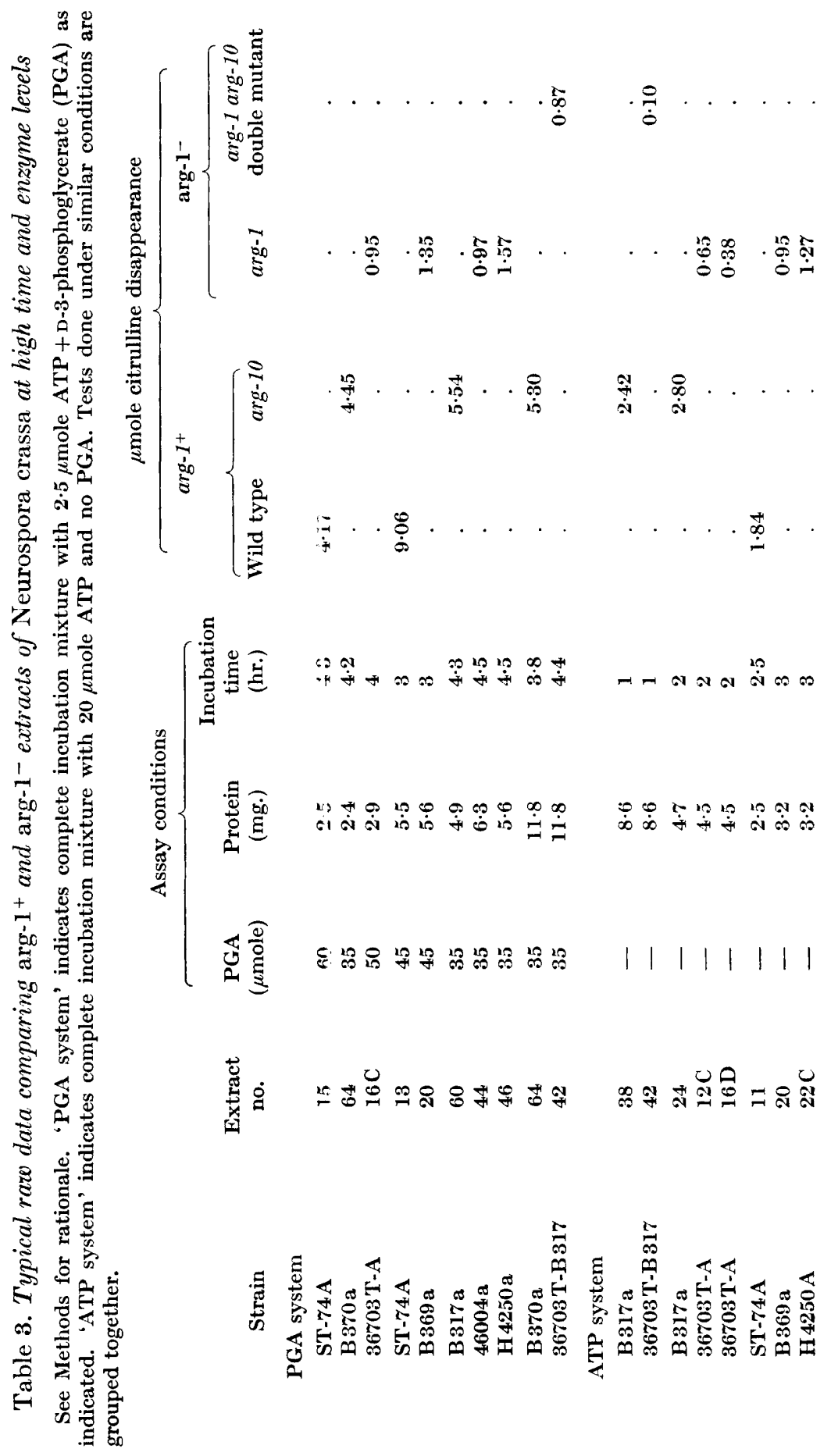




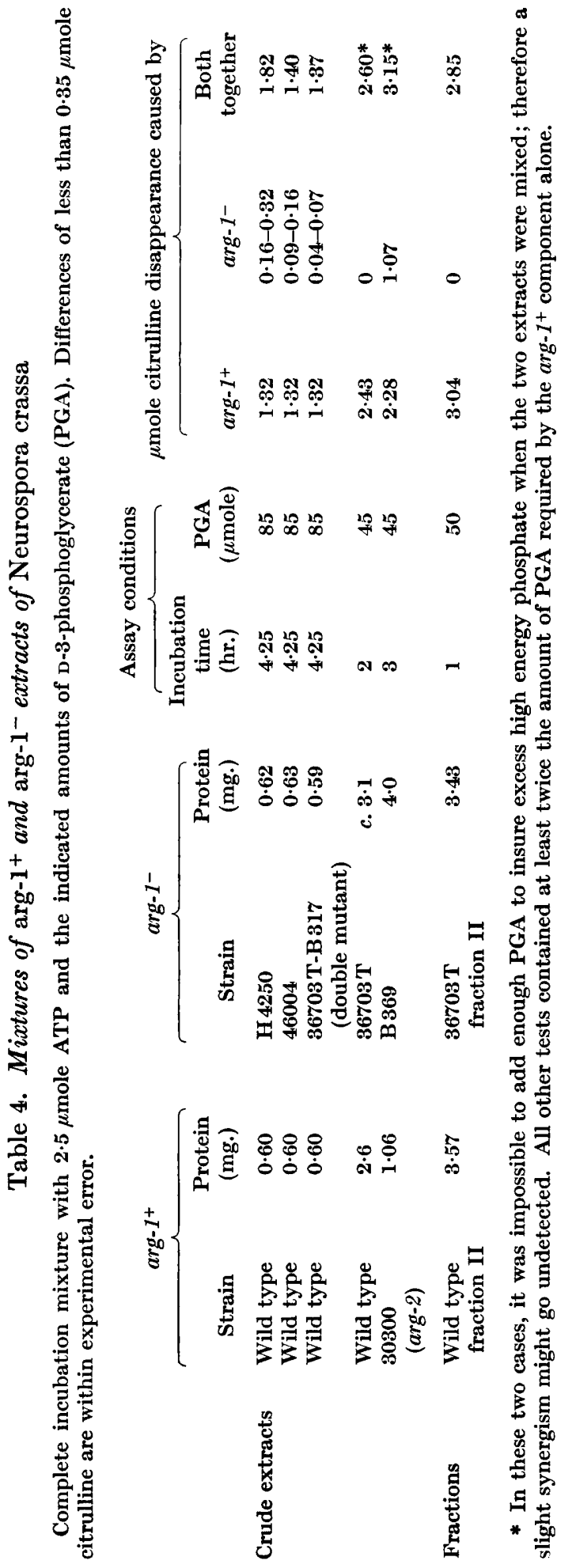


This possibility was ruled out ec mpletely for the arg-1 arg-10 double mutant, since the $\arg -10$ block prevents arginine formation.

Mixing extracts from two different arg-1 mutants was tested in two cases (Table 5); neither mixture show ad synergism. Furthermore, the five arg-1 mutants do not complement in heterocaryons in any combination (Newmeyer, 1957). It is concluded that all five arg-1 mutants involve a simple loss of the same enzyme.

The residual activity of the arg-1 extracts cannot reasonably be ascribed to bacterial action during the rathe : long incubation periods because controls incubated without enzyme never showed any citrulline disappearance, and because of the reproducibility of the activity when any strain was grown repeatedly under the same conditions. The question re nained whether the residual citrulline disappearance was due to condensation or to irrelevant side reactions, as discussed in Methods. To facilitate answering this question, growth conditions were found which gave increased residual activity. But the arg-10 controls grown under these conditions gave unexpected results which should first be discussed.

Anomalous behaviour of arg-19 mutants. The results reported so far indicate that arg-10 strains, grown as in Table 2, gave extracts with completely normal condensing activity. However, when growr for 3 days at low arginine concentrations $(0 \cdot 035$ or $0.07 \mathrm{mg} . / \mathrm{ml}$.) both arg-10 allels s tested gave extracts with very little condensing activity. Four extracts from mycelia grown at $0.07 \mathrm{mg} . / \mathrm{ml}$. had specific activities in the $\mathrm{D}-3-$ phosphoglycerate sys iem of only $0 \cdot 05-0 \cdot 06$; the one extract from mycelium grown at $0.035 \mathrm{mg}$. $/ \mathrm{ml}$. had a specific activity of $0 \cdot 15$.

It was shown that the low activity of these extracts was not due to variations in the amount of grinding, or tc inadequate regeneration of ATP, or to inhibitor production (Table 6 , line 1 ), ancl that only a small part of the reduction in activity could be explained by increased ATPase. Since the defect thus seemed to be a simple loss, it was of interest to assay the defective arg-10 extracts in admixture with arg-1, to test the possibility that one type lacked the condensing enzyme while the other had insufficient pyrophosphatase. Since no extract of an arg-1 single mutant was available for these: tests, an extract of the double mutant was used, which was made from mycelic, grown under conditions which gave normal condensing activity for arg-10 alo xe. No stimulation was found (Table 6, lines 2, 3, and 4); it appears therefore that both arg-1 and defective arg-10 extracts lack the same enzyme.

However, accumulation tests indicated that the low activity of the defective arg-10 extracts did not accurat ly reflect the situation during growth of the cultures. These tests were made by chror atographing undialysed samples of extracts prepared as for enzyme assay. They thowed clearly that the defective arg-10 cultures accumulated large amounts of argininosuccinate and no or negligible amounts of citrulline. Therefore, even at low arginine concentrations, arg-10 must have had condensing activity in vivo; furthermore, if this activity was subnormal, citrulline synthesis must have been suk normal also. In contrast, the arg-1 arg-10 double mutant, grown under the same conditions, accumulated citrulline but not argininosuccinate; this would indicate that it had no condensing activity in vivo. A wildtype culture accumulated neither compound, as expected.

Since at these arginine concentrations $\arg -10$ gave only $0 \cdot 35$ and $0 \cdot 60$ times as much growth as comparable w ld-type cultures, it is quite possible that its extracts 


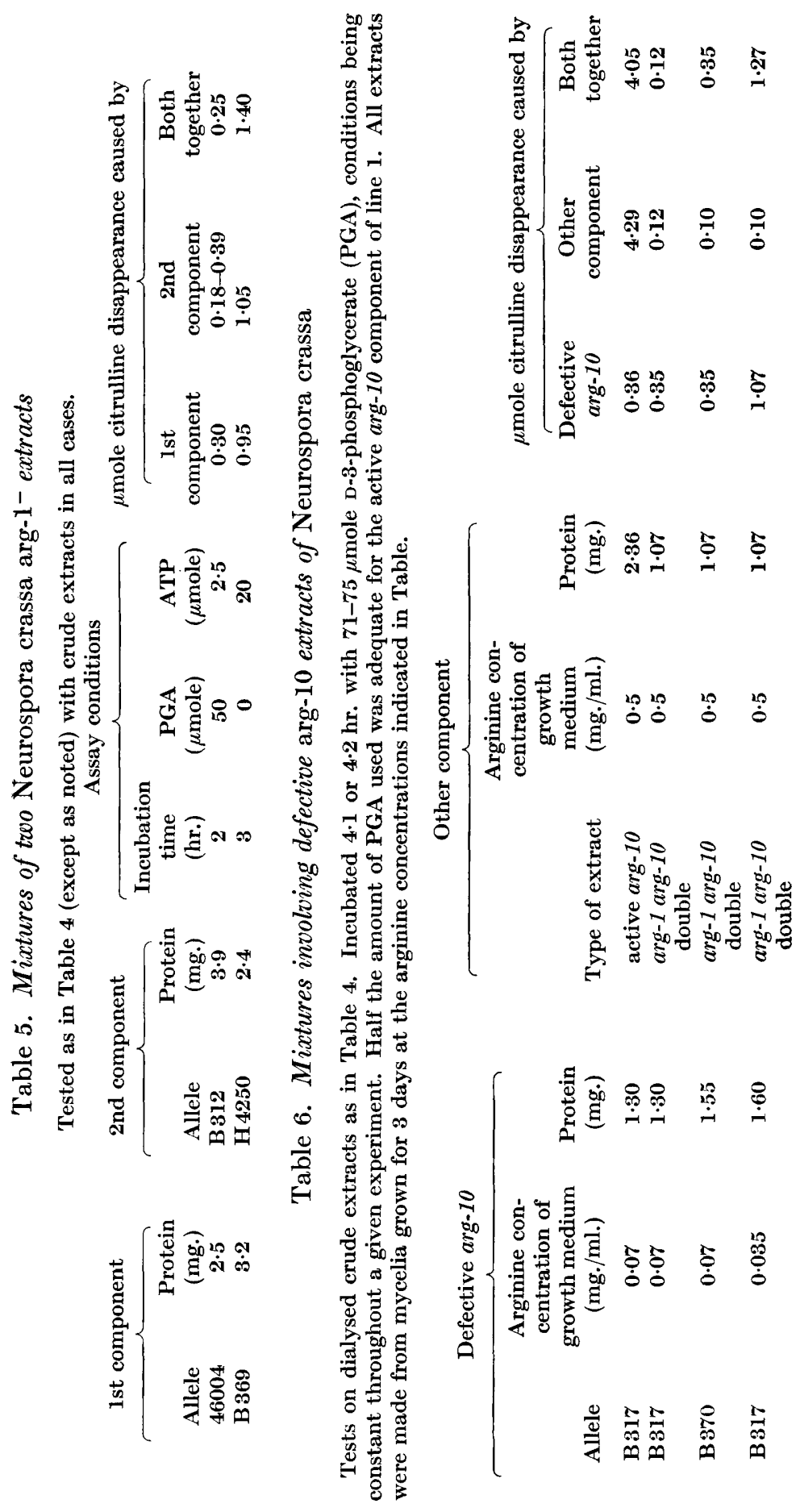


had low activity simply because the cultures were growing slowly, or had even stopped growing, at the time of harvesting. If so, many enzyme activities might be diminished, both inside and outside the arginine pathway; the effect would then be unspecific and unimportant. A specific effect has not been excluded however. Although it was not feasible in this case to run curves of growth $v$. time, such as were run for all other experimental conditions, the available data make it quite unlikely that the $0.07 \mathrm{mg} . / \mathrm{ml}$. cultures had actually stopped growing before they were harvested. Furthermore it appears that the poor growth was not simply due to arginine limitation, since at this same concentration the inbred arg-1 arg-10 double mutant grew nearly as well as the wild type. It is therefore possible that the excessive accumulation of argininosuccinate may interfere with growth; it might also prevent further synthesis of condensing enzyme. It has been shown by accumulation tests that these effects could not occur through depletion of the free amino acid pool; but the effect on condensing enzyme could happen through a repression mechanism (Vogel, 195\%), which could affect citrulline synthesis as well.

Nature of residual arg-1 activity. Both the abnormal fractionation behaviour and the lack of ATP inhibition suggested that the residual activity of the arg-1 extracts was due to loss of citrulline through irrelevant side-reactions (e.g. via citrullinase). Furthermore, the arg-1 activity, at least in two alleles, was found to be largely independent of aspartate, $\mathrm{Mg}^{++}$and $\mathrm{ATP}$, in contrast to the strong dependence of the controls (Table 7). Additional tests on extracts 16 and 40 indicated that no single constituent of the system was required, although multiple omissions decreased the activity somewhat. Adding acetyl glutamate, substituting ADP for ATP, and lowering the $\mathrm{pH}$ to $6 \cdot 1$, all gave slight increases in activity.

Direct evidence for side-reactions was sought by chromatographically testing whether the citrulline disappearance caused by arg-1(36703T) was accompanied by argininosuccinate formation (Table 8). In some cases the arg-1 arg-10 double mutant was used (the arg-10 block being included to prevent the removal, through argininosuccinase and arginase, of any argininosuccinate that might be formed). Of the double mutant extracts used, no. 78 was made from mycelium grown under the same conditions as the active arg-10 control extract, so that the lack of argininosuccinate production could be ascribed to the arg- 1 block. The others (nos. 40 and 48) were prepared under the conditions which gave the defective arg-10 extracts. They could therefore not be used as proof that arg-1 prevents argininosuccinate formation, but, because of their higher activity, they provided the best evidence for extensive side-reactions, and facilitated identification of the side-products.

All the wild-type and active arg-10 control filtrates gave the expected strong argininosuccinate spots. None of the arg-1 or double mutant filtrates showed any argininosuccinate, although the sample sizes were such that if all the missing citrulline had been converted to argininosuccinate, it should have given more than $2 \cdot 5$ times the minimum detectable amount.

Instead of argininosuccinate, the arg-1 and arg-1 arg-10 filtrates each gave four spots detected in the arg-1+ controls; these were tentatively identified as glutamate, alanine, isoleucine and valine. In addition, a trace spot tentatively identified as carbamyl aspartate (detected by Ehrlich's reagent) was sometimes found, as well as dubious traces of ornithine. No arginine was detected, but it would not always have been detectable on these chromatograms. Its detection should be unnecessary, 


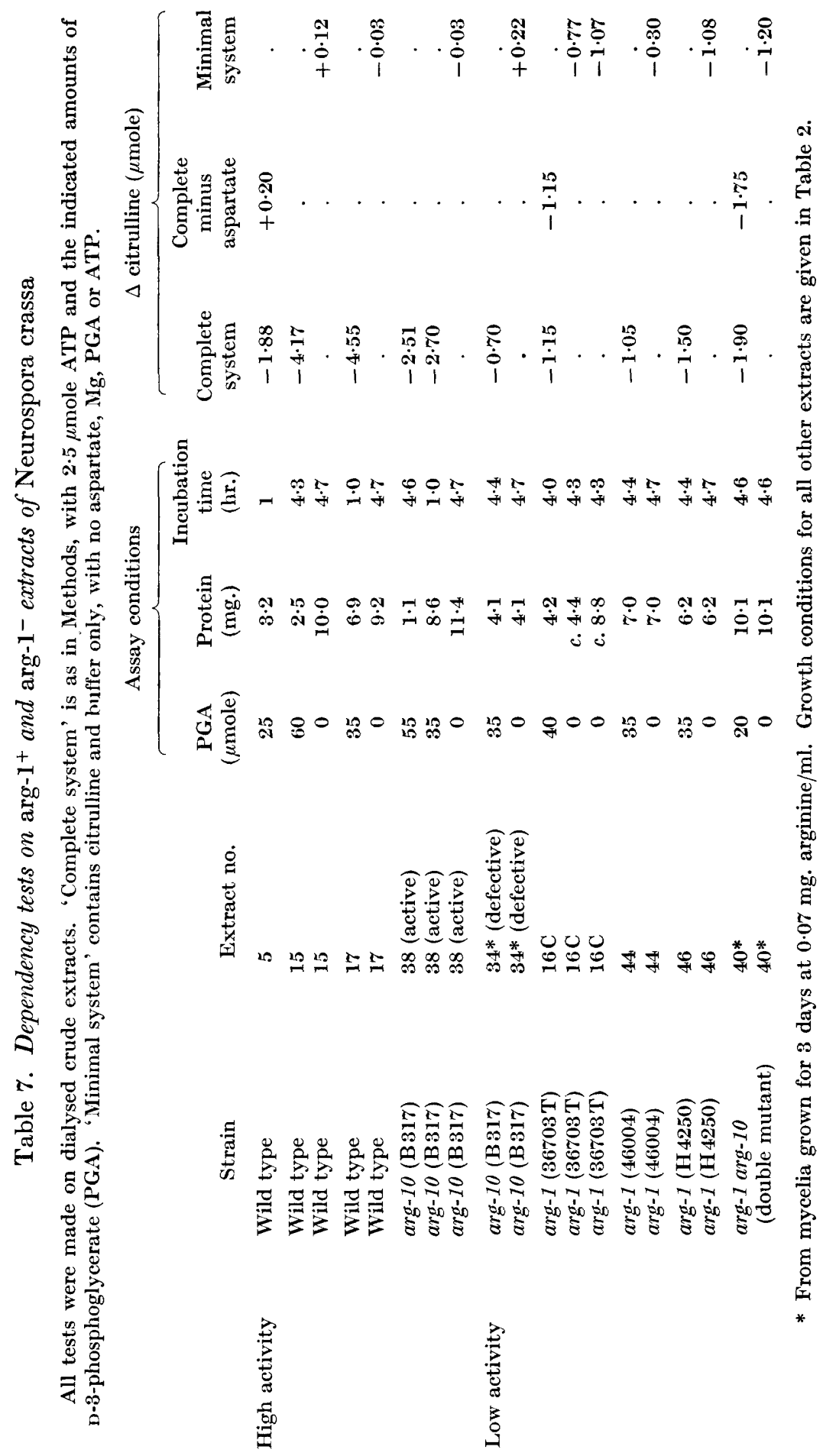


D. Newmeyer

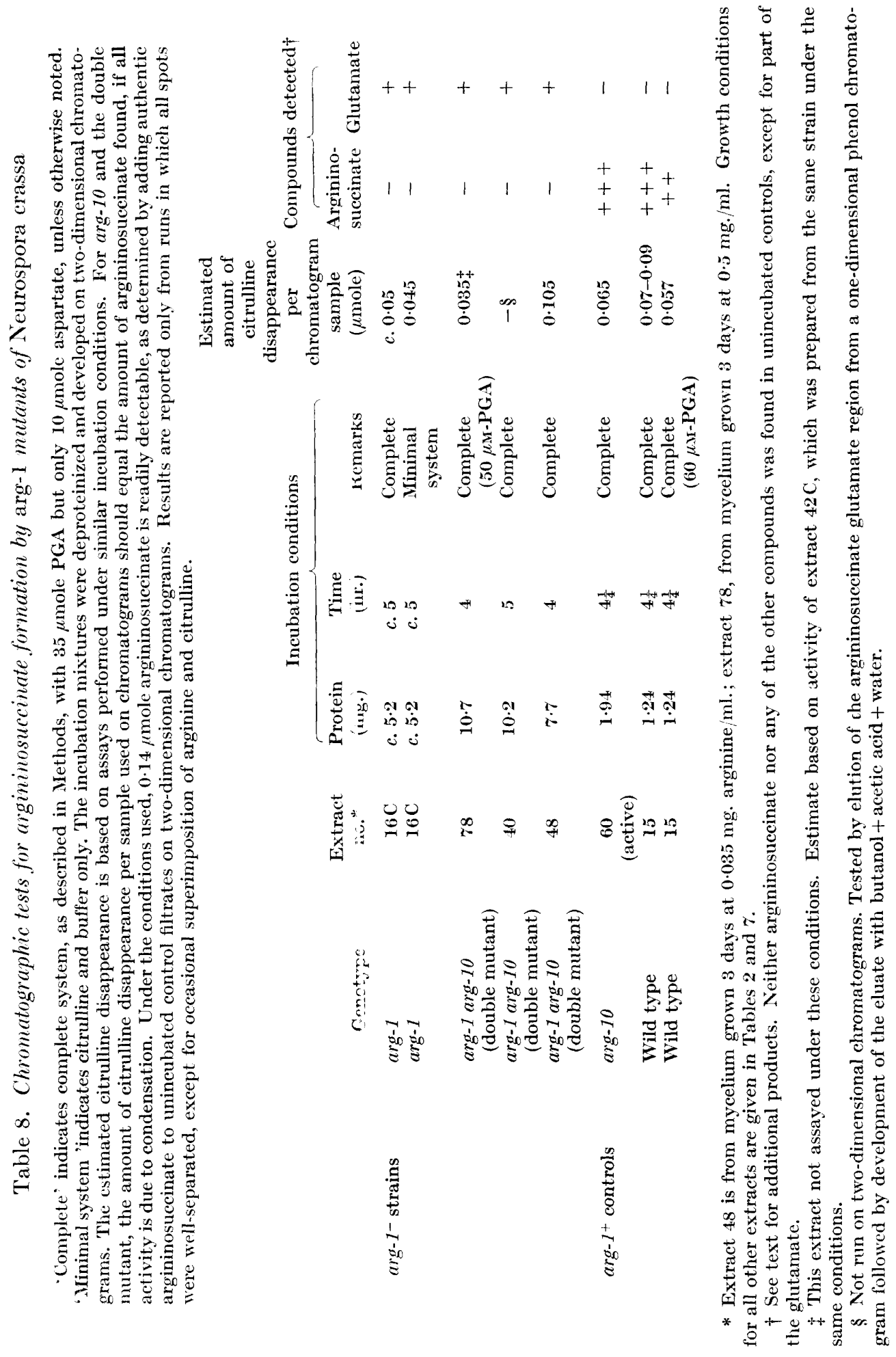


however, because of the inclusion of the arg-10 block. Actually, much of the glutamate and alanine was also formed in the absence of citrulline. The spots tentatively identified as isoleucine and valine, however, were strongly citrulline-dependent. These two spots were identified only by their failure to separate from the added authentic compounds; several other amino acids with similar $\boldsymbol{R}_{\boldsymbol{F}}$ values were not excluded. How citrulline could assist in the formation of isoleucine, valine, or any of these alternative amino acids is not known.

The separation of argininosuccinate and glutamate on two-dimensional chromatograms was unequivocal. On such chromatograms the product in the $\arg -1^{-}$and double mutant filtrates behaved exactly like glutamate. The possibility that arg-1extracts did form argininosuccinate, but immediately destroyed it, e.g. by cyclization (Ratner et al. 1953), was excluded by adding equal amounts of argininosuccinate to samples of a double mutant incubation mixture, before and after incubation. Chromatograms of these two were identical. It is concluded that most or all of the citrulline disappearance caused by arg-1(36703T) extracts was unrelated to condensation. The results of the dependency tests and the lack of ATP inhibition indicated that this was probably true also for alleles B369 and H4250. A trace of true condensing activity in mutant 46004 was not excluded.

Nature of residual activity in defective arg-10 extracts. A dependency test on a defective arg-10 extract suggested that the remaining activity was really due to condensation, since it vanished completely in the absence of aspartate $+\mathrm{Mg}^{++}+\mathrm{ATP}$ (Table 7). The low protein concentration of these extracts precluded the conversion of enough citrulline to argininosuccinate to test this chromatographically.

Argininosuccinase. Fincham \& Boylen (1957) showed that the four arg-10 mutants lacked detectable argininosuccinase; they mentioned that the arg- 1 allele $36703 \mathrm{~T}$ had about the wild-type concentration of this enzyme. Results obtained here, with the extracts recorded in Table 2 confirmed their results and showed that the other four arg-1 alleles were also highly active in this respect.

\section{DISCUSSION}

The enzyme missing from the arg- 1 extracts is almost certainly the condensing enzyme itself, rather than the stimulatory enzyme, inorganic pyrophosphatase. Inasmuch as inorganic pyrophosphate is involved in several essential reactions and inhibits several others, it seems most unlikely that a deficiency of pyrophosphatase would result in viable mutants with an essentially complete requirement for a single growth factor. This conclusion is strengthened by the essentially complete absence of condensing activity in the arg-1 mutants. Since the arg-1 mutants lacked activity under all conditions tested, and since insertion of this block into the double mutant prevented argininosuccinate accumulation in vivo, it seems likely that arg- 1 is the primary locus determining ability to synthesize the condensing enzyme. The defective arg-10 extracts also appear to lack condensing enzyme, but the inadequate supplement used here may well cause drastic reductions in many enzyme activities. Therefore it is doubtful whether arg-10 has any specific effect on the condensing enzyme. If there is such an effect, it must be a secondary one, since arg-10 strains have normal activity when grown at high arginine concentrations. 
This work was supported in part by a grant from the Nutrition Foundation, Inc., U.S.A., in part by a research grant (C 2167) from the National Cancer Institute of the National Institutes of Health, Public Health Service, U.S.A., and in part by a grant from the American Cancer Society. The author is indebted to Dr Sarah Ratner for samples of barium argininosuccinate and rabbit muscle extract and to Mrs Eivor Högström for technical assiste nce.

\section{REFERENCES}

Beadle, G. \& Tatum, E. L. (194.5). Neurospora II. Methods of producing and detecting mutations concerned with nutritional requirements. Amer. J. Bot. 32, 678.

Fincham, J. R. S. (1958). The role of chromosomal loci in enzyme formation. Proc. 10th int. Congr. Genet. 1, 355.

Fincham, J. R. S. \& Boylen, J. B. (1957). Neurospora crassa mutants lacking argininosuccinase. J. gen. Microbiol. 16, 438.

Gornall, A. G., Bardawill, C. J. \& David, M. M. (1949). Determination of serum proteins by means of the biuret reaction. J. biol. Chem. 177, 751 .

Newmeyer, D. (1957). Arginine synthesis in Neurospora crassa: Genetic studies. J. gen. Microbiol. 16, 449.

OGinsky, E. L. \& Gehrig, R. F. (1952). The arginine dihydrolase system of Streptococcus faecalis. II. Properties of arginine desimidase. J. biol. Chem. 198, 799.

RATNER, S. (1955). Enzymatic syl thesis of arginine (condensing and splitting enzymes). In Methods in Enzymology, 2, 356. Ed. by S. P. Colowick and N. O. Kaplan. New York: Academic Press Ine.

Ratner, S. \& Petrack, B. (1951). Biosynthesis of urea. III. Further studies on arginine synthesis from citrulline. J. biol. Chem. 191, 693.

Ratnen, S. \& Petrack, B. (1953a . Biosynthesis of urea. IV. Further studies on condensation in arginine synthesis from citrulline. J. biol. Chem. 200, 161.

Ratner, S. \& Petrack, B. $(1953 b)$. The mechanism of arginine synthesis from citrulline in kidney. J. biol. Chem. 200, 175 .

Ratner, S. \& Petrack, B. (1956). Conversion of argininosuccinic acid to citrulline coupled to ATP formation. Arch. Biochem. Biophys. 65, 582.

Ratner, S., Petrack, B. \& Rochovansky, O. (1953). Biosynthesis of urea. V. Isolation and properties of argininosuccinic xcid. J. biol. Chem. 204, 95.

Vogel, H. J. (1957). Repression and induction as control mechanisms of enzyme biogenesis: 'The 'adaptive' formation of acetylornithinase. In The Chemical Basis of Heredity, p. 276. Ed. by W. D. McElroy and B. Glass. Baltimore: Johns Hopkins Press. Yanofsky, C. \& St Lawrence, P. (\$960). Gene action. Annu. Rev. Microbiol. 14, 311. 